\title{
Transuterine transport of small- and medium-sized molecules deposited in the uterus in gilts
}

\author{
S. Viring, S. Einarsson, B. Jones* and K. Larsson \\ Department of Obstetrics and Gynaecology and *Department of Clinical Chemistry, Faculty of \\ Veterinary Medicine, The Swedish University of Agricultural Sciences, S-750 07 Uppsala 7, \\ Sweden
}

\begin{abstract}
Summary. Radiolabelled compounds were mixed with seminal plasma and placed in the uterine lumen of anaesthetized gilts which were killed $5 \min (\mathrm{N}=1)$ and $1 \mathrm{~h}(\mathrm{~N}$ $=2$ ) later. After $1 \mathrm{~h}$ the distribution patterns of the 2 compounds placed in different horns were similar, indicating transuterine transport. Transuterine transport had begun by $5 \mathrm{~min}$ after deposition of seminal plasma. In all 3 gilts, the labelled substances had moved to the anterior segments of the oviduct.
\end{abstract}

\section{Introduction}

In pigs semen is deposited almost directly into the uterine lumen during coitus or at artificial insemination. Most of the seminal plasma and a large part of the spermatozoa disappear during the first hours after natural or artificial insemination (du Mesnil du Buisson \& Dauzier, 1955; Rigby, 1964; First, Short, Peters \& Stratman, 1968). The survival of spermatozoa is greatest at the uterotubal junction, which is presumed to play a role similar to that of the cervix in other mammals (du Mesnil du Buisson \& Dauzier, 1955). The rapid loss of semen from the uterus is to some extent caused by backflow through the cervical canal (McKenzie, Miller \& Bauguess, 1938; Burger, 1952; Viring, 1978). Powerful uterine contractions occur during oestrus in pigs (Zerobin, 1968; Bower, 1974; Viring \& Einarsson, 1980a) and such activity is primarily responsible for the rapid transport of spermatozoa within the reproductive tract.

Transuterine migration of zygotes occurs in sows and has been demonstrated experimentally by Dziuk, Polge \& Rowson (1964). The mechanism is not well understood but probably involves muscular activity of the uterine wall. Transuterine transport of semen by way of the corpus uteri has not been described.

The purpose of the present study was therefore to investigate whether transuterine movement of semen occurs in oestrous pigs.

\section{Materials and Methods}

The 3 crossbred (Swedish Landrace and Swedish Yorkshire breed) gilts used were checked daily for oestrus in the presence of a vasectomized boar. The gilts were used for the experiments approximately $24 \mathrm{~h}$ after the onset of their second or third oestrus.

Anaesthesia was induced with a $5 \%$ solution of thiopentone sodium (Pentothal: Abbott) injected into an ear vein. The uterine horns were localized and exposed after incision along the linea alba. Insemination was performed very slowly, directly through a cannula into the uterine 
horn lumen, approximately $10 \mathrm{~cm}$ from the uterine body in a tubal direction. No backflow was allowed during the insemination. Each uterine horn was inseminated with $35 \mathrm{ml}$ seminal plasma mixed with $2 \mathrm{ml} 0.9(\mathrm{w} / \mathrm{v}) \mathrm{NaCl}$ containing a labelled compound (Table 1). The seminal plasma was collected from a vasectomized boar and was sperm free. Gilts 1 and 2 were slaughtered at 2 $h$ and Gilt 3 at 5 min after the insemination. Any semen passing out through the vulva was collected.

Table 1. Details of the radiolabelled substances added to seminal plasma and surgically inseminated into oestrous gilts

\begin{tabular}{|c|c|c|c|c|c|}
\hline Gilt & $\begin{array}{l}\text { Uterine } \\
\text { horn }\end{array}$ & Additive* & $\begin{array}{l}\text { Molecular } \\
\text { weight }\end{array}$ & $\begin{array}{l}\text { Sp. act. } \\
(\mu \mathrm{Ci} / \mathrm{mg})\end{array}$ & $\begin{array}{c}\text { Amount } \\
\text { inseminated } \\
(\mu \mathrm{Ci})\end{array}$ \\
\hline \multirow[t]{2}{*}{$\begin{array}{l}1 \text { and } \\
2\end{array}$} & Right & $\begin{array}{l}{ }^{131} \text { I-labelled } \\
\text { polyvinyl- } \\
\text { pyrrolidone }\end{array}$ & $\begin{array}{l}30000- \\
40000\end{array}$ & $20-60$ & 400 \\
\hline & Left & ${ }^{59} \mathrm{Fe}$ citrate & 335 & $3000-30000$ & 400 \\
\hline \multirow[t]{2}{*}{3} & Right & $\begin{array}{l}{ }^{123} \text { I-labelled } \\
\text { polyvinyl- } \\
\text { pyrrolidone }\end{array}$ & $\begin{array}{l}30000- \\
40000\end{array}$ & $20-60$ & 400 \\
\hline & Left & ${ }^{59} \mathrm{Fe}$ citrate & 335 & $3000-30000$ & 400 \\
\hline
\end{tabular}

- From AB Atomenergi Isotopservice Studsvik, Nyköping, Sweden.

The reproductive tracts were removed immediately after stunning and bleeding. Oviducts, uterine horns, uterine body and cervix were separated and prepared as described by Einarsson, Jones, Larsson \& Viring (1980) and the radioactivity of the different parts of the tract was also measured as before (Einarsson et al., 1980).

Table 2. Single and median values of the amounts of ${ }^{131} \mathrm{I}$-labelled polyvinylpyrrolidone $\left({ }^{131} \mathrm{I}\right)$ and ${ }^{59} \mathrm{Fe}$ citrate $\left({ }^{59} \mathrm{Fe}\right)$ recovered from Gilts 1 and 2 , expressed as a percentage of the total radioactivity recovered from the tract

\begin{tabular}{|c|c|c|c|c|c|c|c|c|c|c|}
\hline & \multicolumn{4}{|c|}{ Gilt 1} & \multicolumn{4}{|c|}{ Gilt 2} & & \\
\hline & \multicolumn{2}{|c|}{ Left } & \multicolumn{2}{|c|}{ Right } & \multicolumn{2}{|c|}{ Left } & \multicolumn{2}{|c|}{ Right } & \multicolumn{2}{|c|}{ Median values } \\
\hline & ${ }^{131} \mid$ & ${ }^{59} \mathrm{Fe}$ & ${ }^{131} 1_{I}$ & ${ }^{39} \mathrm{Fe}$ & ${ }^{131} I$ & ${ }^{59} \mathrm{Fe}$ & ${ }^{131} \mathbf{I}$ & ${ }^{59} \mathrm{Fe}$ & ${ }^{131}$ I & ${ }^{39} \mathrm{Fe}$ \\
\hline Oviduct $\left(\times 10^{-3}\right)$ & & & & & & & & & & \\
\hline I & 1.0 & 0.8 & 0.9 & 0.8 & $4 \cdot 0$ & 1.0 & $4 \cdot 6$ & 0.7 & $2 \cdot 5$ & 0.8 \\
\hline II & 0.8 & $2 \cdot 6$ & $1 \cdot 3$ & 0.2 & $4 \cdot 0$ & 0.9 & 3.5 & $22 \cdot 2$ & 2.4 & 1.8 \\
\hline III & 1.2 & 0.9 & 1.6 & 0.6 & 3.8 & 1.5 & 3.5 & 1.5 & $2 \cdot 6$ & $1 \cdot 2$ \\
\hline IV & 1.4 & 0.4 & 1.8 & 0.2 & 3.9 & 0.9 & 3.9 & 0.7 & 2.9 & 0.6 \\
\hline $\begin{array}{l}\text { Median } \\
\text { values }\end{array}$ & $1 \cdot 1$ & 0.9 & 1.5 & 0.4 & $4 \cdot 0$ & 1.0 & $3 \cdot 7$ & $1 \cdot 1$ & & \\
\hline Uterine horn & & & & & & & & & & \\
\hline Anterior & 0.003 & 0.003 & 2 & 3 & 0.2 & 0.2 & 0.8 & 0.7 & & \\
\hline Middle & 0.3 & 0.6 & 48 & 51 & 6 & 5 & 12 & 10 & & \\
\hline Posterior & 2 & 3 & 47 & 43 & 32 & 32 & 44 & 36 & & \\
\hline Uterine body & & 0.09 & 0.08 & & & 1 & 1 & & & \\
\hline Cervix & & 0.2 & 0.1 & & & 11 & 2 & & & \\
\hline Vagina & & 0.05 & 0.03 & & & 3 & 3 & & & \\
\hline
\end{tabular}




\section{Results}

The amounts of radioactivity recovered were $55.6-56.6 \%$ for ${ }^{59} \mathrm{Fe}$ citrate and $59.6-63.6 \%$ for ${ }^{131}$ I-labelled polyvinyl pyrrolidone for Gilts 1 and 2 ( $1 \mathrm{~h}$ after insemination) and $58 \cdot 2 \%{ }^{59} \mathrm{Fe}$ and $54.3 \%{ }^{131}$ I for Gilt 3 ( $5 \mathrm{~min}$ after insemination).

The backflow through the cervix, calculated as a percentage of inseminated dose, was $30.7-39.9 \%$ for ${ }^{59} \mathrm{Fe}$ and $24.4-28.1 \%$ for ${ }^{131} \mathrm{I}$ in Gilts 1 and 2 , and 28.7 and $8.9 \%$ respectively in Gilt 3.

The distribution patterns of radioactivity in the reproductive tracts are presented in Tables 2 and 3. The patterns were similar for the 2 compounds in Gilts 1 and 2, indicating that transuterine movement had taken place. In both gilts higher quantities of both substances were recovered from the right uterine horn. Recovered activity was approximately equal within the oviducts except for Segment II of the right oviduct in Gilt 2. Transuterine transport of the compounds had begun by $5 \mathrm{~min}$ after insemination (Table 3) but most of the material was still where it was deposited. Both compounds were also recovered from all oviduct segments.

Table 3. Amounts of ${ }^{125}$ I-labelled polyvinylpyrrolidone ( $\left.{ }^{125} \mathrm{I}\right)$ and ${ }^{59} \mathrm{Fe}$ citrate $\left({ }^{59} \mathrm{Fe}\right)$ recovered from Gilt 3 expressed as a percentage of the total radioactivity recovered from the tract

\begin{tabular}{lccccc}
\hline & \multicolumn{2}{c}{ Left } & & \multicolumn{2}{c}{ Right } \\
\cline { 5 - 6 } & ${ }^{125 I}$ & ${ }^{59} \mathrm{Fe}$ & & ${ }^{125} \mathrm{I}$ & ${ }^{59} \mathrm{Fe}$ \\
\hline Oviduct $\left(\times 10^{-3}\right)$ & & & & \\
I & 1.8 & 11.8 & & 2.4 & 12.2 \\
II & 2.0 & 9.6 & & 2.1 & 8.9 \\
III & 1.2 & 6.0 & & 1.2 & 8.7 \\
IV & 0.7 & 4.2 & & 1.9 & 9.0 \\
Uterine horn & & & & \\
$\quad$ Anterior & 0.01 & 0.2 & & 0.4 & 0.03 \\
Middle & 5 & 36 & & 41 & 0.5 \\
$\quad$ Posterior & 10 & 61 & & 42 & 2 \\
Uterine body & & 0.3 & 0.2 & \\
Cervix & & 0.4 & 0.4 & \\
Vagina & & 0.2 & 0.3 & \\
\hline
\end{tabular}

\section{Discussion}

The results clearly demonstrate that a transuterine transport of the radioactive compounds, and presumably also seminal plasma, took place and had begun $5 \mathrm{~min}$ after the intrauterine deposition of seminal plasma.

A similar disproportionate distribution in the total amount of recovered radioactivity between right and left uterine horns was demonstrated after cervical insemination of labelled compounds mixed with seminal plasma (Einarsson et al., 1980). The reason for this is not known. Viring \& Einarsson (1980b) did not find any correlation between numbers of large follicles/ovulations and numbers of recovered spermatozoa in the adjacent horn after natural service and an ovarian influence on the adjacent horn in this respect is therefore most unlikely.

The appearance of the labelled compounds in the upper part of the oviducts within 5 min of deposition shows that the transport speed within the reproductive tract of oestrous gilts is very fast, as also demonstrated by Baker \& Degen (1972). Since spermatozoa and fluid may pass through the oviducts into the abdominal cavity, as recorded by Horne \& Thibault (1962) for 
women, the amount of radioactivity or the number of spermatozoa recovered in oviduct segments at any time does not reflect the total number transported along the oviducts, but only the population in transit.

This work was supported by grants from The Swedish Council for Forestry and Agricultural Research.

\section{References}

Baker, R.D. \& Degen, A.A. (1972) Transport of live and dead spermatozoa within the reproductive tract of gilts. J. Reprod. Fert. 28, 369-377.

Bower, R.E. (1974) Factors affecting myometrial activity in the pig. Dissertation, University of Minnesota.

Burger, J.F. (1952) Sex physiology of pigs. Onderstepoort J. vet. Res., Suppl. 2.

Dziuk, PJ., Polge, C. \& Rowson, L.E. (1964) Intrauterine migration and mixing of embryos in swine following egg transfer. J. Anim. Sci. 23, 37-42.

du Mesnil du Buisson, F. \& Dauzier, L. (1955) Distribution et résorption du sperme dans le tractus génital de la truie: survie des spermatozoides. Annls Endocr. 16, 413-422.

Einarsson, S., Jones, B., Larsson, K. \& Viring, S. (1980) Distribution of small- and medium-sized molecules within the genital tract of artificially inseminated gilts. J. Reprod. Fert. 59, 453-457.

First, N.L., Short, R.E., Peters, J.B. \& Stratman, F.W. (1968) Transport and loss of boar spermatozoa in the reproductive tract of the sow. J. Anim. Sci. 27, 1037-1040.
Horne, H.W., Jr \& Thibault, J.P. (1962) Sperm migration through the human female reproductive tract. Fert. Steril. 13, 444-447.

McKenzie, F.F., Miller, J.C. Bauguess, L.C. (1938) The reproductive organs and semen of the boar. Res. Bull. Mo. agric. Exp. Stn No. 279.

Rigby, J.P. (1964) The fate of spermatozoa in the genital tract of the sow following artificial insemination. Proc. Sth Int. Congr. Anim. Reprod. \& A. I., Trento, pp. 421-425.

Viring, S. (1978) Sperm distribution in the reproductive tract of mated gilts. Proc. 13th Nordic vet. Congr., Abo, p. 312, Abstr.

Viring, S. \& Einarsson, S. (1980a) Effect of boar seminal plasma on uterine and oviductal motility in oestrous gilts. Acta vet. scand. (in press).

Viring, S. \& Einarsson, S. (1980b) Sperm distribution in the reproductive tract of naturally inseminated gilts. Nord. Vet.-Med. (in press).

Zerobin, K. (1968) Untersuchungen über die Uterusmotorik des Schweines. Zentbl. VetMed. 15, 740 and 798.

Received 30 November 1979 